\title{
A FURTHER APPROACH TO THE ESTABLISHMENT OF A FISTULA IN THE VAS DEFERENS OF RAMS*
}

\author{
A. TADMOR, H. SCHINDLER $\dagger$ AND ORA KEMPENICH-PINTO $\dagger$ \\ The Kimron Veterinary Institute, Bet Dagan, and \\ $\dagger$ The Volcani Institute of Agricultural Research, Rehovot, Israel
}

(Received 23rd Fune 1969)

\begin{abstract}
Summary. In nine out of eleven operations, fistulae were established in the vas deferens of rams. This was accomplished by incising the vas deferens and suturing the orifice to a small surgical opening in the dorsal surface of the scrotum, close to the incision through which the vas deferens had been exposed.
\end{abstract}

In order to obtain epididymal semen from live animals, fistulae have been established in the vas deferens of bulls and rams by a small number of investigators. Bennett \& Rowson (1963) cannulated the vas deferens of one bull from the posterior side of the scrotum. Amann, Hokanson \& Almquist (1963) used a cannula and a special collection system attached to the scrotum for obtaining epididymal semen from two bulls. White, Larsen \& Wales (1959) made fistulae in the vas deferens of rams on the anterior surface of the scrotum by securing the wall of the incised vas to the margin of the surgical opening of the skin. Some of their fistulae remained patent for considerable lengths of time. In short-term experiments, Ewy, Bielanski \& Zapletal (1963) obtained epididymal semen from rams through a cannula inserted into the vas deferens from the anterior side of the scrotum.

In our previous experiments, we obtained fistulae of the vas deferens of rams by using a polyethylene cannula which was inserted into the vas deferens and held in place by a silver disc sewn to the scrotal skin (Tadmor \& Schindler, 1966).

In the second series of experiments, the establishment of a fistula in the vas deferens of rams was attempted by using a surgical procedure applied in human surgery. In this procedure, the orifice of the severed vas deferens was encompassed with a skin auto-graft of the scrotum. However, the success of the twelve operations carried out was only moderate (Tadmor, Schindler \& KempenichPinto, 1968).

In the present paper, a third approach to the establishment of a fistula in the vas deferens of rams is described.

Merino rams over 2 years of age were used. Vetacalm $(1.5 \%$ thioxanthen

* Contribution from The Kimron Veterinary Institute, Bet Dagan and The Volcani Institute of Agricultural Research (N.U.I.A.), Rehovot, Israel. 1969 Series; No. 1526-E. 
derivate, Veterinaria AG, Zürich) was given intravenously before the operation, until the interdigital and corneal reflexes were diminished. In addition, general anaesthesia was given intravenously when necessary.

A longitudinal incision of 4 to $6 \mathrm{~cm}$ was made on the posterior surface of the scrotal skin, between the head of the epididymis and the inguinal canal and about $2 \mathrm{~cm}$ lateral to the median line of the scrotum. After blunt dissection of the subcutaneous tissue, the vas deferens enveloped in the tunica vaginalis parietalis was pulled through the surgical opening and separated from the rest of the spermatic cord at a length of about 3 to $4 \mathrm{~cm}$ (Pl. 1, Fig. 1). The tunica was opened and a 3- to 5-mm longitudinal incision was made on the exposed vas deferens. A metal probe was inserted a few millimetres deep in the distal direction to ensure that the longitudinal incision was made properly. A polyethylene cannula (about $1 \mathrm{~mm}$ outer and about $0.5 \mathrm{~mm}$ inner diameter; Portex Intravenous Tubing, Size 48 or 46; Portland Plastics Ltd, Hythe, Kent, England), was inserted through the incision in the direction of the tail of the epididymis (Pl. 1, Fig. 2) until it reached the point where the convolution of the vas deferens began.

Close to the upper margin of the surgical opening, an additional opening, $1 \mathrm{~cm}$ long, was made in the scrotal skin by perforating the subcutis and cutis from the inner side. The small opening was made on either the median or lateral side of the large surgical opening, according to the position of the vas deferens.

The free end of the cannula was pulled through the small opening of the skin and the orifice of the vas deferens was brought close to it (Pl. 1, Fig. 3). The mucosa of the vas deferens was attached to the margins of the small opening and the muscular layer of the vas deferens was sutured to the scrotal skin with the use of an atraumatic needle (Pl. 1, Fig. 4). Care was taken not to perforate the mucosa of the vas deferens with the atraumatic needle. The large surgical opening was then also closed. Antibiotics were applied to the surgical opening, as well as intramuscularly, for 3 days following the operation.

Eleven operations were carried out. In nine, patent fistulae were established after the cannula had been expelled, usually a few days after the operation. These remained open for the following lengths of time during which semen was collected regularly: 21 days (one fistula), 35 days (one fistula), 60 days (three fistulae), 150 days (three fistulae) and 270 days (one fistula). Two operations were unsuccessful as no semen was obtained, and inflammation of the testis and of the epididymis developed immediately after the operation.

Semen was collected either by massaging the epididymis or by allowing the ram to mount a ewe.

This method for establishment of a fistula appeared to be more satisfactory than our two previous ones, resulting in a higher percentage of success and a longer average life of the fistulae. The surgical procedure was found to be simpler than those described previously and the operating time was short.

This investigation was supported by a grant from the U.S. Department of Agriculture under P.L. 480. The authors are indebted to A. Shoob (Tel Aviv University) for the photography. 
PLAIE

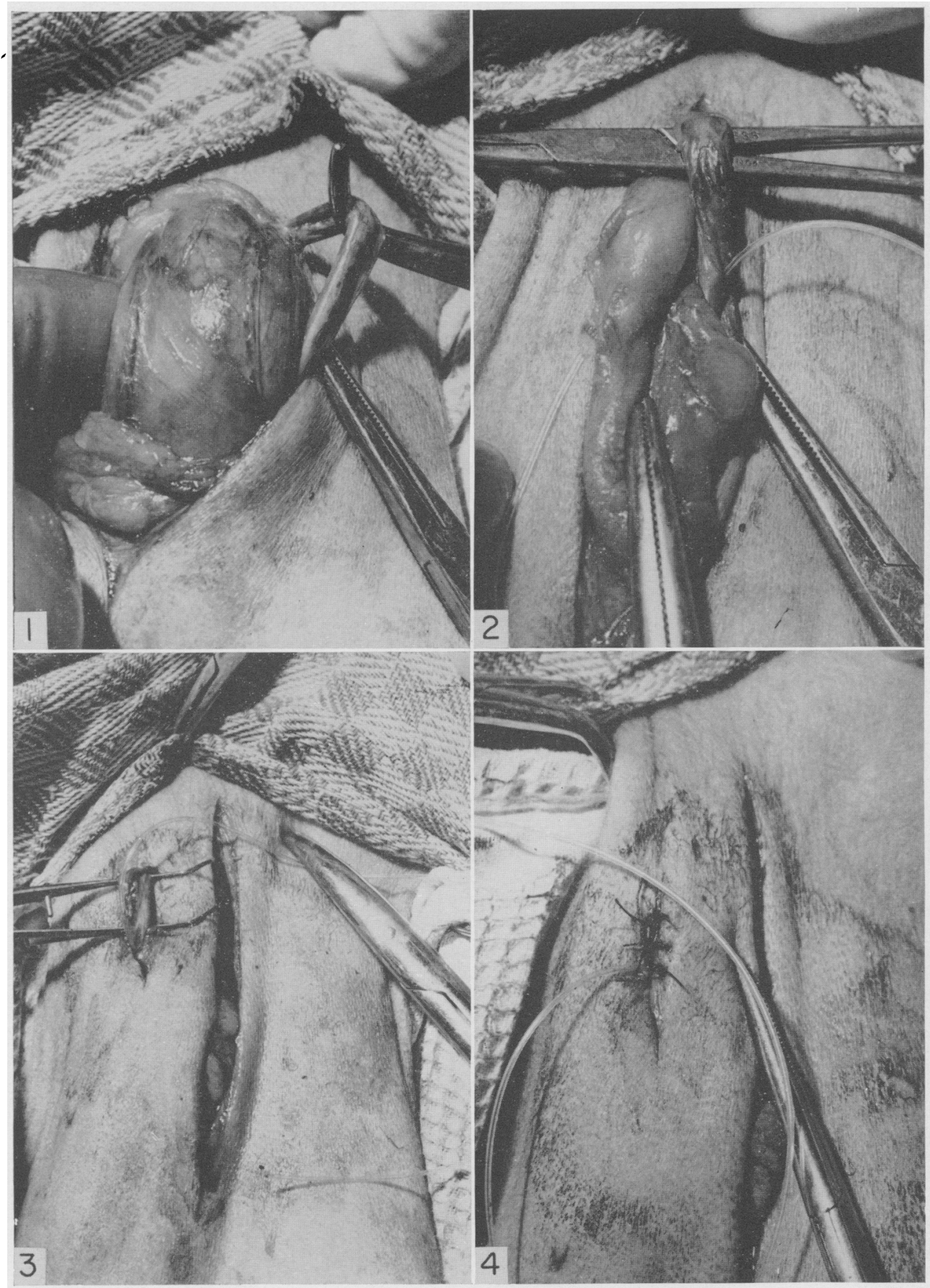

Fic. I. Separation of the vas deferens from the spermatic cord.

Fis; 2. Inscetion of a cammula in the vas deforens.

lies. 3. The orifiec of the vas deferems with the cannula is brought clese to the small opening in the scrotial skin.

Fici. 4. The orifiee of the vats deferens is sutured to the small opening.

(Ficing f) . i2t 


\section{REFERENCES}

Amann, R. P., Hokanson, J. F. \& Almquist, J. O. (1963) Cannulation of the bovine ductus deferens for quantitative recovery of epididymal spermatozoa. F. Reprod. Fert. 6, 65.

Bennetr, J. P. \& Rowson, L. E. (1963) A fistula for the collection of epididymal semen from the bull. 7. Reprod. Fert. 6, 61 .

EWY, Z., BIELANSKI, W. \& ZapLETAL, Z. (1963) Influence of oxytocin on spermatozoa transport in the ductus deferens of the ram. Bull. Acad. pol. Sci., Cl. II, Sér. Sci. biol. 11, 145.

TADMOR, A. \& Schindler, H. (1966) Establishment of a fistula in the vas deferens of rams. Istael J. agric. Res.-Ktavim, 16, 157.

TAdmor, A., Schindler, H. \& Kempenich-Pinto, ORA. (1968) Establishment of a fistula in the vas deferens of rams. In: Factors Acting in Long-term Storage of Sperm in vivo. Final Report of Research. U.S. Dept. Agric. Proj. No. A10-AH-13.

White, I. G., LARsen, L. H. \& WALEs, R. G. (1959) Method for the in vivo collection of epididymal spermatozoa and for their comparison with ejaculated cells. Fert. Steril. 10, 571. 